\title{
The Bacteriology of Acute Necrotizing Ulcerative Gingivitis*
}

\author{
Walter J. Loesche, $†$ Salam A. Syed, $\ddagger$ Barbara E. Laughon, $\S$ and \\ Janice Stoll\|
}

Accepted for publication 25 September 1981

\begin{abstract}
Plaque SAmPLes from 22 ulcerated sites in eight patients with ANUG were cultured using quantitative anaerobic procedures and were examined microscopically. The partial characterization of the predominant cultivable flora revealed a constant flora comprised of a limited number of bacterial types and a variable flora composed of a heterogeneous array of bacterial types. This constant flora would appear to be pathognomonic of acute necrotizing ulcerative gingivitis (ANUG) and included the various Treponema and Selenomonas sp., which comprised about 32 and 6\%, respectively, of the microscopic count; B. melaninogenicus ssp. intermedius and Fusobacterium sp., which averaged 24 and 3\%, respectively, of the viable count. One week of metronidazole treatment caused a prompt resolution of clinical symptoms, which coincided with a significant reduction in the plaque proportions of the Treponema sp., B. melaninogenicus ssp., intermedius and Fusobacterium sp. for at least 2 to 3 months following treatment. Thus, the same anaerobic species which were numerically associated with the ANUG lesion were also selectively reduced in the plaque flora following resolution of the infection. This supports a role for the above species in the ulcerative stage of the lesion but does not demonstrate that these specific anaerobes initiated the infection. Although not confirmed by the data, it was proposed that these particular anaerobic species gained ascendency in the plaque as a result of being selected through the availability of host-derived nutrients in individuals who had undergone certain physiological and psychological stresses.
\end{abstract}

Acute necrotizing ulcerative gingivitis (ANUG) is a relatively rare clinical entity, which generally has been described in young individuals. ${ }^{1}$ The incidence of ANUG increases under conditions of physiological ${ }^{2}$ and psychological stress, ${ }^{1,3}$, a phenomenon which has been well documented among military personnel. ${ }^{1,4,5}$ A fusospirochetal bacterial component has been identified on the basis of microscopic examination of plaque samples, ${ }^{6,7}$ the demonstration of spirochetes in the tissue of the lesion ${ }^{8}$ and the prompt resolution of the clinical lesion upon treatment with penicillin or metronidazole. ${ }^{9-11}$ The antimicrobial studies indicate that the microbes present or dominant in the plaque contribute to the clinical symptoms, but this does not demonstrate that these organisms initiated the infection. Rather, the fu-

\footnotetext{
* This research was supported by Public Health Service Grants DE 03011, DE 02731 and F32 DE 05172 from the National Institute of Dental Research.

$\dagger$ Professor of Dentistry and Microbiology, University of Michigan School of Dentistry, Ann Arbor, MI 48109.

$\ddagger$ Associate Research Scientist, Dental Research Institute.

$\S$ Post Doctoral Scholar, School of Dentistry.

|| Research Assistant, School of Dentistry.
}

sospirochetal complex could be opportunistic pathogens overgrowing in the plaque during those periods when the tissue defense mechanisms had been compromised by stress, ${ }^{1}$ nutritional disturbances ${ }^{2}$ or viral infections, ${ }^{12}$ among others. ${ }^{3}$

The evidence for the involvement of the fusospirochetal organisms is based upon the microscopic appearance of plaque smears. Only a few attempts at cultivation of this flora have been reported and these, with the exception of the extensive investigations by Rosebury and his colleagues, ${ }^{7}$ have been unsuccessful. ${ }^{3,13}$ Rosebury used anaerobic methods and complex media to isolate what appeared to be representative members of the plaque flora. These studies were not quantitative in nature and resulted in the isolation and partial characterization of 58 strains comprising 11 taxonomic groups. Various large combinations of these strains were capable of causing abscess formation when injected into the groin of a guinea pig. ${ }^{14}$ Macdonald et al. ${ }^{15}$ simplified these combinations to a group of four organisms, which contained Bacteroides melaninogenicus but no spirochetes or fusiforms. Eventually, B. melaninogenicus was identified as the essential pathogen in this mixture. ${ }^{16}$ Thus, the one 
cultural study of plaque taken from ANUG sites implicated $B$. melaninogenicus rather than the fusospirochetal organisms as the potential pathogen.

Anaerobic culturing methodology has improved in recent years, to the extent that the most fastidious anaerobic species can be cultured. ${ }^{17}$ However, the quantitative isolation of the various spirochetal species remains a problem because these organisms are lysed by the procedures used to disrupt the plaque to obtain the single cells necessary for the isolation of pure colonies. ${ }^{18}$ Accordingly, spirochetes have been identified and quantitated only by microscopic methods. In the present study plaque samples taken from discrete sites of ulceration were cultured using quantitative anaerobic procedures and were examined microscopically.

\section{MATERIALS AND METHODS}

Patients. Eight patients with one or more sites of interproximal necrosis and ulceration were seen in the research clinic. Four patients had one to three lesions and were afebrile. Another four patients had multiple sites of ulceration, were irritable and three of them had a mild fever. Three of these four patients had been unsuccessfully treated by a regimen of mechanical debridement, peroxide mouthwashes and oral hygiene. After bacteriological samples were taken from representative ulcers in these latter patients, they were given metronidazole, $250 \mathrm{mg}$, three times daily for 7 days. Bacteriological sampling was repeated immediately after the completion of the metronidazole and again 2 to 3 months later.

Cultural Procedure. Plaque was removed from discrete sites of ulceration by a curette, and the adherent plaque on the tip was transferred to a vial containing $0.5 \mathrm{ml}$ of a reduced transport fluid (RTF) without EDTA. ${ }^{19}$

The plaque sample was immediately placed within the anaerobic chamber ${ }^{20}$ and after dispersing for 20 seconds with a Vortex mixer, a $50 \mu \mathrm{l}$ aliquot was removed for microscopic examination. The remaining sample was diluted to $4 \mathrm{ml}$, sonically dispersed for 20 seconds with a Kontes sonifier, ${ }^{*}$ serially diluted in RTF and plated automatically with a spiral plater $\dagger$ on a variety of media. This dispersal procedure appears to give optimal recoveries of Gram-negative organisms from plaque samples, but lyses the spirochetes.

The total anaerobic count, the count of black-pigmented Bacteroides (BPB) species, Capnocytophaga species, Fusobacterium species and the red-brown-pigmented colonies of Actinomyces odontolyticus were obtained from growth on enriched trypticase soy agar (ETSA) ${ }^{21}$ Either all or representative colonies of BPB were subcultured and speciated on their ability to use glucose, to hydrolyze esculin and to produce indole using the scheme shown in Table 1. Actinomyces viscosus and

* Kontes Glass Company, Vineland, NJ.

† Spiral Systems, Inc., Cincinnati, $\mathrm{OH}$.
Table 1

Scheme Used to Differentiate Black Pigmented Bacteroides Species

\begin{tabular}{cccc}
\hline Species & $\begin{array}{c}\text { Glucose } \\
\text { fermenta- } \\
\text { tion }\end{array}$ & $\begin{array}{c}\text { Indole } \\
\text { produc- } \\
\text { tion }\end{array}$ & $\begin{array}{c}\text { Esculin } \\
\text { hydrolysis }\end{array}$ \\
\hline B. melaninogenicus & & & \\
ssp. intermedius & + & + & - \\
ssp. melaninogenicus & + & - & + \\
B. gingivalis & - & + & - \\
\hline
\end{tabular}

Actinomyces naeslundii were differentiated and enumerated on a cadmium sulfate-metronidazole selective medium. ${ }^{22}$ Streptococcus sanguis and Streptococcus mutans were identified by their colony morphology on MM10 sucrose agar. ${ }^{23}$ Veillonella colonies were enumerated on a medium containing the MM10 base minus the sucrose and blood, but supplemented with lactate, vancomycin ${ }^{24}$ and a $0.004 \%$ bromocresol purple indicator. The total count of facultative organisms was obtained from growth on ETSA agar containing $20 \mu \mathrm{g} / \mathrm{ml}$ of metronidazole, which was incubated anaerobically.

In certain plaque samples the proportions of the cited species accounted for about $20 \%$ of the total viable count. In order to determine the identity of the other colonies, each colony on a high dilution plate that contained from 20 to 100 colonies was subcultured and partially characterized by its Gram stain and its ability to grow aerobically, ferment glucose, reduce nitrate, produce indole, hydrolyze starch and esculin and to exhibit gelatinase and catalase activity.

From the aliquot removed for microscopic examination, $10 \mu \mathrm{l}$ was placed on a glass slide under a $22 \times 30$ $\mathrm{mm}$ cover glass, sealed and viewed by dark-field microscopy. Either 200 organisms or the number of organisms in 20 high power fields (hpf) were enumerated, depending on which event occurred first. The single cells were identified as Treponema species (spirochetes), large spirochetes, selenomonads, motile rods, fusiforms, nonmotile rods and cocci. ${ }^{25}$ The proportions of each of these categories in the sample were determined. The protein in the sample was measured by a fluorometric method using fluorescamine. ${ }^{26}$ The presence of blood and tissue debris in the plaque samples, however, reduced its usefulness in quantitation of the plaque sample.

Statistical Analyses. The total counts and the proportions of organisms in each cultural and microscopic sample were determined and statistically analyzed using the computer programs available in the Michigan terminal system. Comparisons between independent samples were analyzed by the parametric Student $t$ test and the nonparametric Kruskal Wallis ranking procedure. ${ }^{27}$ The effect of metronidazole treatment on the bacterial flora was evaluated by the paired $t$ test and the Wilcoxon test.

\section{RESULTS}

Patients with ANUG were rarely encountered. In 3 
years only eight patients with ulceration were examined and from these, 22 sites were cultured. For the first three patients all isolates appearing on an ETSA plate were subcultured and partially characterized. Five hundred and twenty two isolates were obtained, which on the basis of the nine taxonomic characteristics used, could be placed into about 70 groups. In order to reduce this variability, some characteristics that were of a low frequency within a Gram stain category were omitted so as to provide the listing of the groups shown in Table 2 . Even so, some 31 groupings could be identified.

The most frequently encountered groups were $B . \mathrm{mel}$ - aninogenicus ssp. intermedius (present in 11/11 sites); a Gram-positive anaerobic, asaccharolytic, nitrate negative rod (10/11 sites); Fusobacterium species (11/11 sites); Gram-positive facultative streptococci that were either esculin negative or positive (7/11 sites) and an anaerobic coccus that was asaccharolytic, nitrate negative and esculin variable (7/11 sites) (Table 2$)$. No obvious pattern was discernible except that $B$. melaninogenicus ssp. intermedius accounted for $18 \%$ of the total isolates, mainly because it was so prominent in patients 1 and 3 (Table 2). Patient 2 has low proportions of $B$. melaninogenicus ssp. intermedius isolates, but had high proportions of

Table 2

Predominant Cultivable Flora Isolated From ANUG Sites

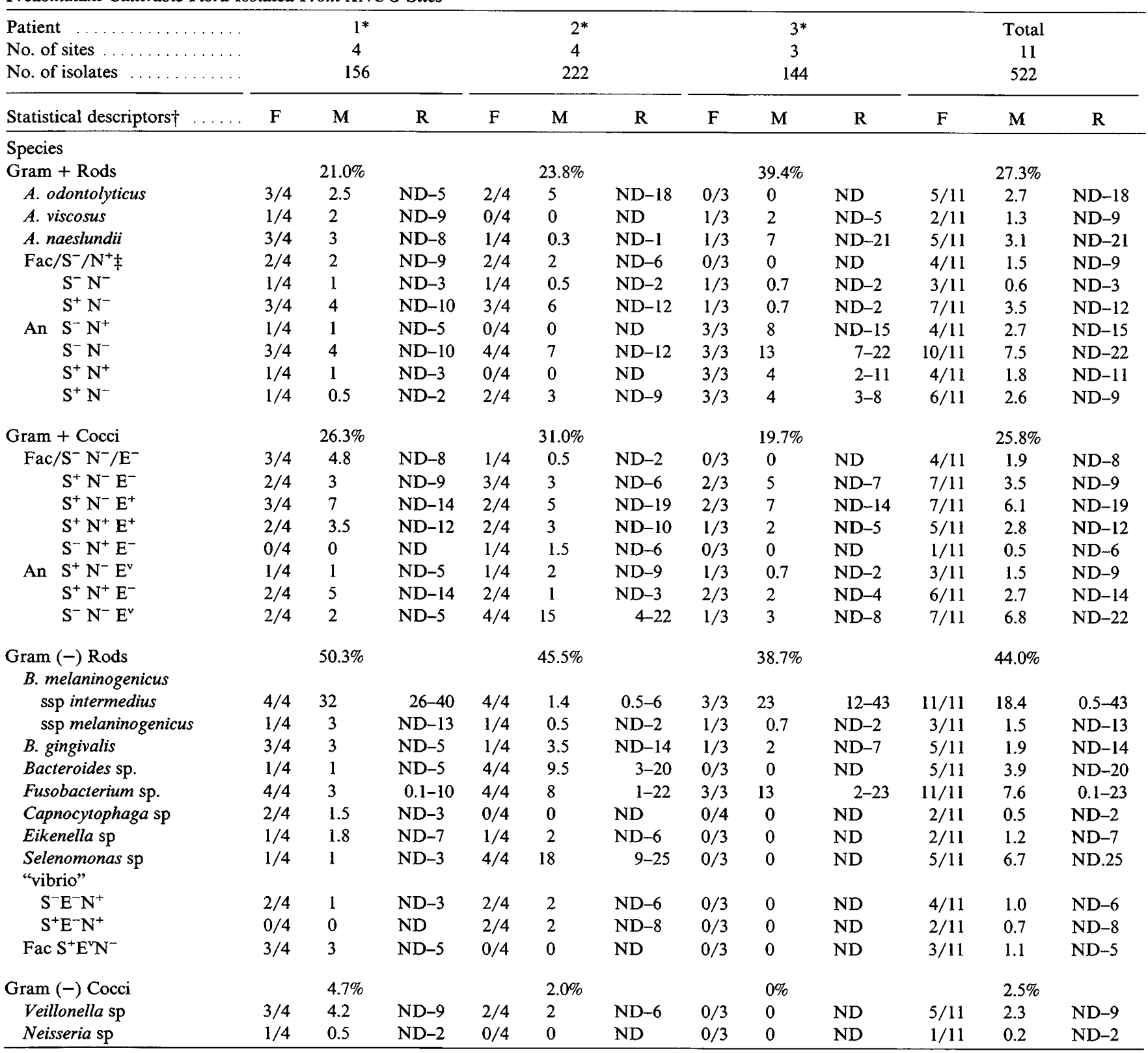

* Mean percentage for each individual derived by averaging the percentages from each of the sites samples in each subject.

$\dagger \mathrm{F}=$ frequency, $\mathrm{M}=$ mean, $\mathrm{R}=$ range; $\mathrm{ND}=$ not detected in dilution ranges examined.

$\ddagger$ Biochemical descriptors: $\mathrm{S}=$ saccharolytic, $\mathrm{N}=$ nitrate reduction, $\mathrm{E}=$ esculin hydrolysis, $+=$ positive, $-=\mathrm{negative}, \mathrm{v}=\mathrm{variable}$, An $=$ anaerobic, $\mathrm{Fac}=$ facultative. 
Selenomonas sp. and nonpigmented Bacteroides sp., both of which were rarely encountered in the other patients.

This partial characterization of each isolate indicated great variability between sites, even within the same mouth, and was most time consuming. Accordingly, the plaques from the subsequent patients, as well as those from the first three patients, were analyzed by enumerating those species which could be identified reliably by their colony morphology on selective or nonselective media. Only the black-pigmented bacteroides species were subcultured and speciated according to the scheme given in Table 1.

Three of the patients had a temperature of about $100^{\circ} \mathrm{F}$, had multiple sites of ulceration and had been refractory to conventional treatment. The other five patients had no fever at the time of sampling, had limited sites of ulceration and had not been treated previously. The plaque flora removed from the sites of ulceration in these two groups of patients was compared in terms of levels (numbers) of the bacteria in the plaque samples (Table 3), or the proportions of these bacteria in the samples (Table 4).

More bacteria were cultured from plaques removed from the febrile patients (Table 3). However, no significant differences, with one exception, were found when the levels of the various bacteria in the plaques taken from the febrile patients were compared by either the Student $t$ test or the Kruskal-Wallis test with their levels in the plaques taken from the nonfebrile patients. The exception was the significantly higher levels of $A$. odontolyticus in the febrile plaques (Table 3 ).
The proportions of the identified species in the plaque samples were calculated by dividing the level of each species in the plaque by the total number of cultivable colony forming units (CFU) in the plaque. Also the proportion of each morphological entity seen in the microscopic count was determined by dividing the levels of the morphological entity by the total number of organisms counted microscopically. There were no differences in the proportions of the various identified organisms in plaques taken from the febrile or the nonfebrile patients when analyzed by either the Student $t$ test or the Kruskal-Wallis test (Table 4).

In both groups $B$. melaninogenicus ssp. intermedius was the most prominent species demonstrated by the cultural method and Treponema sp. were the dominant morphologic types identifiable in the microscopic flora (Table 4). The difference in the levels, but not the proportions of $A$. odontolyticus did not warrant the separation of the febrile group from the nonfebrile group. Accordingly, the values from all the patients were combined (Tables 3 and 4). B. melaninogenicus ssp. intermedius, the Treponema sp. and the Fusobacterium sp. were found in all plaque samples. $B$. melaninogenicus ssp. intermedius accounted for $24 \%$ of the cultural count, and the Treponema sp. for $30 \%$ of the microscopic count.

The Fusobacterium sp. represented about $2.6 \%$ and the Capnocytophaga sp. about $0.8 \%$ of the cultural count. Fusiforms, which would include both Fusobacterium and Capnocytophaga sp., comprised $4.9 \%$ of the microscopic count. The Selenomonas sp. were present in most microscopic samples, ${ }^{17-20}$ but were not readily identifiable on

Table 3

Levels of Suspected Odontopathic Organisms in the Predominant Cultivable Flora of Plaque Taken From ANUG Sites in Febrile and Nonfebrile Patients

\begin{tabular}{|c|c|c|c|c|c|}
\hline & \multicolumn{4}{|c|}{ Patients } & \multirow{2}{*}{$\begin{array}{l}\text { Fre- } \\
\text { quency }\end{array}$} \\
\hline & Febrile (12)* & & Nonfebrile $(10)^{*}$ & Total $(22)^{*}$ & \\
\hline & \multicolumn{4}{|c|}{ C.F.U. $\times 10^{6}$ organisms per plaque sample } & \\
\hline Total count .... & $171.3 \pm 250.0 \dagger$ & & $65.6 \pm 66.0$ & $123.0 \pm 194.0$ & \\
\hline Facultative count & $22.5 \pm 38.2$ & & $13.5 \pm 19.6$ & $18.0 \pm 30.0$ & \\
\hline $\begin{array}{l}\text { B. melaninogenicus ssp. } \\
\text { intermedius }\end{array}$ & $20.2 \pm 19.8$ & & $19.7 \pm 42.0$ & $19.9 \pm 31.0$ & $22 / 22$ \\
\hline B. gingivalis & $<0.01 \ddagger$ & & $0.4 \pm 1.3$ & $0.2 \pm 0.9$ & $5 / 22$ \\
\hline Capnocytophaga sp. & $0.4 \pm 0.9$ & & $0.5 \pm 0.6$ & $0.5 \pm 0.8$ & $15 / 22$ \\
\hline Fusobacterium sp. & $3.6 \pm 6.1$ & & $1.0 \pm 1.2$ & $2.4 \pm 4.7$ & $22 / 22$ \\
\hline A. odontolyticus & $6.8 \pm 12.3$ & $(0.05) \S$ & $1.0 \pm 2.0$ & $4.1 \pm 9.5$ & $18 / 22$ \\
\hline A. viscosus & $0.5 \pm 0.5$ & & $0.2 \pm 0.2$ & $0.3 \pm 0.4$ & $14 / 18$ \\
\hline A. naeslundii & $<0.01$ & & $0.01 \pm 0.03$ & $<0.01$ & $1 / 18$ \\
\hline S. sanguis & $1.1 \pm 12.4$ & & $0.9 \pm 1.8$ & $1.0 \pm 1.6$ & $16 / 18$ \\
\hline S. mutans & $<0.01$ & & $<0.01$ & $<0.01$ & $3 / 18$ \\
\hline Veillonella & $3.7 \pm 9.2$ & & $2.7 \pm 6.4$ & $3.1 \pm 7.6$ & $13 / 18$ \\
\hline $\begin{array}{l}\text { Microscopic count } \\
\text { organisms } / \mathrm{hpf}\end{array}$ & $46.0 \pm 45.0$ & & $41.0 \pm 100.0$ & $43.1 \pm 78$ & \\
\hline Protein & $70.0 \pm 6.0$ & & $63.0 \pm 13.0$ & $67.0 \pm 10.0$ & \\
\hline
\end{tabular}

* Number of sites in parentheses.

$\dagger$ Average \pm standard deviation.

$\ddagger<0.01$ means that species was not detected at lowest dilution.

$\S P$ value for Kruskal-Wallis Test, significance between febrile and nonfebrile. 
Table 4

Proportions of Suspected Odontopathic Organisms in the Plaque Taken From ANUG Sites in Febrile and Nonfebrile Patients

\begin{tabular}{|c|c|c|c|}
\hline \multirow[b]{2}{*}{ Bacterial species } & \multicolumn{2}{|c|}{ Patients } & \multirow[b]{2}{*}{ Total $(22)^{*}$} \\
\hline & Febrile $(12)^{*}$ & $\begin{array}{l}\text { Nonfebrile } \\
(10)^{*}\end{array}$ & \\
\hline & \multicolumn{2}{|c|}{ Cultivable Flora } & $\%$ \\
\hline $\begin{array}{l}\text { B. melaninogenicus ssp. } \\
\text { intermedius }\end{array}$ & $26.4 \pm 22.4 \dagger$ & $21.0 \pm 20.0$ & $24.0 \pm 21.1$ \\
\hline$B$. gingivalis & $<0.01$ & $1.9 \pm 6.0$ & $0.9 \pm 4.0$ \\
\hline Capnocytophaga sp. & $0.3 \pm 0.4$ & $1.4 \pm 3.0$ & $0.8 \pm 1.8$ \\
\hline Fusobacterium sp. & $2.4 \pm 1.6$ & $2.7 \pm 3.0$ & $2.6 \pm 2.3$ \\
\hline A. odontolyticus & $3.2 \pm 4.1$ & $1.2 \pm 2.0$ & $2.3 \pm 3.3$ \\
\hline A. viscosus & $2.1 \pm 2.5$ & $1.0 \pm 2.0$ & $1.5 \pm 2.1$ \\
\hline A. naeslundii & $<0.01$ & $0.2 \pm 0.6$ & $0.1 \pm 0.4$ \\
\hline S. sanguis & $3.5 \pm 4.1$ & $1.5 \pm 2.0$ & $2.4 \pm 3.0$ \\
\hline S. mutans & $<0.01 \ddagger$ & $<0.01$ & $<0.01$ \\
\hline Veillonella sp. & $1.6 \pm 1.6$ & $5.1 \pm 12.0$ & $3.5 \pm 9.5$ \\
\hline Facultative organisms & $28.9 \pm 23.8$ & $18.0 \pm 18.0$ & $23.4 \pm 21.0$ \\
\hline \multicolumn{4}{|c|}{ Per Cent of Microscopic Counts } \\
\hline Treponema sp. & $29.0 \pm 17.0$ & $31.0 \pm 25.0$ & $30.2 \pm 21.1$ \\
\hline Large & $12.0 \pm 13.0$ & $7.0 \pm 9.0$ & $9.9 \pm 11.5$ \\
\hline Selenomonads & $5.0 \pm 2.0$ & $9.0 \pm 9.0$ & $6.9 \pm 7.3$ \\
\hline Motile rods & $2.0 \pm 2.0$ & $2.0 \pm 4.0$ & $2.2 \pm 2.9$ \\
\hline Fusiforms & $5.0 \pm 5.0$ & $5.0 \pm 6.0$ & $4.9 \pm 5.3$ \\
\hline Rods \& Cocci & $61.0 \pm 16.0$ & $54.0 \pm 19.0$ & $57.4 \pm 18.0$ \\
\hline
\end{tabular}

$*$ Number of sites given in parentheses.

$\dagger$ Average \pm standard deviation.

$\ddagger$ No significant differences found between plaques taken from febrile or nonfebrile patients. Student $t$ or Kruskal-Wallis tests.

the nonselective ETSA medium. A. odontolyticus was present in the majority of the plaque samples. No other sought-after organism was found either in all the samples or in high proportions in the samples.

Metronidazole has been effective in the treatment of ANUG patients. ${ }^{9-11}$ As this agent is active only against anaerobic species, ${ }^{28,29}$ it was of interest to determine what changes metronidazole treatment would cause among the monitored plaque anaerobic species. Three patients who had been refractory to conventional treatment were given metronidazole for 1 week. Prior to treatment, the plaque from 10 sites in these patients harbored primarily an anaerobic flora with high proportions of B. melaninogenicus ssp. intermedius and Treponema sp. (Table 5). Immediately after the metronidazole treatment the same sites were no longer ulcerated and had decreased plaque, as evident by the reduced viable and microscopic counts. The plaque was now dominated by facultative organisms, which accounted for $79 \%$ of the flora.

Anaerobic species such as $B$. melaninogenicus ssp. intermedius, Fusobacterium sp., Selenomonas sp. and Treponema sp. were significantly reduced (Table 5). Among the monitored facultative and microaerophilic species, $S$. sanguis and the Capnocytophaga sp. increased significantly (Table 5), as would be expected if the patients took the metronidazole as directed.
This ascendency of the facultative flora did not persist, inasmuch as 2 to 3 months later the proportions of facultative organisms and of $S$. sanguis and Capnocytophaga sp. had returned to or had fallen below pretreatment values. This reemergence of anaerobic species in the plaque was not accompanied by a rebound in the proportions of $\mathrm{B}$. melaninogenicus ssp. intermedius, $\mathrm{Fu}$ sobacterium and Treponema sp., as these organisms were still significantly reduced compared to pretreatment values (Table 5). However, the proportions of these species had increased relative to the immediately-after-treatment values, and in the case of the spirochetes and selenomonads this increase was significant (Table 5). There was no return of the gingivitis to these cultured sites.

\section{DISCUSSION}

The cultural methods used in this investigation permit the isolation of about 60 to $70 \%$ of the organisms that can be counted microscopically. Thirty per cent of the microscopic count of the ANUG plaque samples consisted of the various spirochetal species whereas the remaining $70 \%$ probably represented the organisms that were also enumerated in the viable count. In order to determine the identity of these cultivable organisms, over 500 isolates obtained from 12 diseased sites were subcultured and partially characterized. This combined microscopic-cultural approach revealed both a constant flora comprised of a limited number of bacterial species and a variable flora composed of a heterogeneous array of bacterial types, most of which could not be identified to the genus or species level (Table 2). The constant flora would include the various Treponema sp., B. melaninogenicus ssp. intermedius and the Fusobacterium sp. There was the suggestion that the Selenomonas sp. by virtue of their presence microscopically in most plaque samples and their prominence in the viable count of one patient (patient 2 in Table 2) might also be a member of this constant flora.

This constant flora would appear to be pathognomonic of ANUG. As members of this flora can be identified by either microscopic appearance or by colony morphology on nonselective media, most of these organisms had been previously associated with ANUG. Thus the present bacteriological findings confirm the long-documented association of the fuso-spirochetal organisms in $\mathrm{ANUG}^{6,7}$ and introduce $B$. melaninogenicus ssp. intermedius, and possibly $A$. odontolyticus and the various Selenomonas sp., as contributors to the pathosis. Macdonald et al. ${ }^{15}$ described an experimental fusospirochetal infection in guinea pigs, in which B. melaninogenicus was demonstrated to be the essential pathogen. The taxonomic status of oral isolates of $B$. melaninogenicus has been clarified recently, ${ }^{30}$ and it is likely that the proteolytic black-pigmented bacteroides strains which Macdonald studied would now be classified as Bacteroides gingivalis. Thus, the demonstration of the involvement of $B$. 
Table 5

Effect of One Week Metronidazole Treatment on Proportions of Suspected Odontopathic Organisms in Plaque Taken From ANUG Sites

\begin{tabular}{|c|c|c|c|}
\hline \multirow{3}{*}{ No. of Sites } & \multirow[b]{2}{*}{ Prior to treatment } & \multicolumn{2}{|c|}{ After treatment } \\
\hline & & Immediately & 2 to 3 Mos. \\
\hline & $10(3)$ & $10(3)$ & $8(2)$ \\
\hline \multicolumn{4}{|c|}{ Percent of Cultivable Flora } \\
\hline $\begin{array}{l}\text { B. melaninogenicus ssp. } \\
\text { intermedius }\end{array}$ & $26.9 \pm 22.0^{*}$ & $0.02 \pm .04$ & $2.7 \pm 7.2$ \\
\hline B. gingivalis & $<.1$ & $<.1$ & $<.1$ \\
\hline Capnocytophaga sp. & $1.4 \pm 2.6$ & $5.0 \pm 6.9$ & $0.3 \pm 0.3$ \\
\hline Fusobacterium sp. & $3.1 \pm 1.4$ & $0.8 \pm 1.4$ & $0.6 \pm 0.6$ \\
\hline A. odontolyticus & $1.7 \pm 1.9$ & $-0.2 \pm 0.4$ & $5.3 \pm 13.5$ \\
\hline A. viscosus & $2.3 \pm 2.5$ & $0.9 \pm 1.5$ & $0.2 \pm 0.5$ \\
\hline A. naeslundii & $<.1 \pm<.1$ & $0.1 \pm 0.4$ & $4.4 \pm 11.0$ \\
\hline S. sanguis & $3.2 \pm 3.6$ & $25.9 \pm 20.7$ & $3.0 \pm 7.0$ \\
\hline S. mutans & $<.1 \pm<.1$ & $0.7 \pm 2.0$ & $0.6 \pm 1.1$ \\
\hline Veillonella sp. & $1.3 \pm 1.5$ & $1.2 \pm 3.3$ & $1.2 \pm 1.1$ \\
\hline Facultative organisms & $28.9 \pm 23.7$ & $79.1 \pm 26.7$ & $15.3 \pm 12.1$ \\
\hline \multicolumn{4}{|c|}{ Percent of Microscopic Count } \\
\hline Treponema sp. & $32.6 \pm 20.1$ & $2.4 \pm 3.4$ & $\rightarrow(.04) \leftarrow 12.4 \pm 12.0$ \\
\hline Selenomonas & $7.3 \pm 10.0$ & $0.3 \pm 0.9$ & $3.2 \pm 3.1$ \\
\hline Motile rods & $0.6 \pm 0.6$ & $1.0 \pm 2.1$ & $4.5 \pm 4.0$ \\
\hline Fusiforms & $1.7 \pm 1.4$ & $4.9 \pm 13.9$ & $10.5 \pm 13.3$ \\
\hline Rods \& Cocci & $69.0 \pm 15.0$ & $93.0 \pm 6.0$ & $70.2 \pm 18.3$ \\
\hline Total Count $\times 10^{6} \mathrm{CFU}$ & $150 \pm 278$ & $33 \pm 28$ & $90 \pm 103$ \\
\hline $\begin{array}{l}\text { Microscopic count per high } \\
\text { power field }\end{array}$ & $48 \pm 111$ & $6 \pm 4$ & $7 \pm 6$ \\
\hline
\end{tabular}

melaninogenicus ssp. intermedius in the ANUG lesion may indeed be new. (J. Slots, at SUNY in Buffalo reports a similar finding, personal communication.) Rosebury et. al. ${ }^{7}$ found spirilla organisms in $56 \%$ of their ANUG cases. The present cultural study identified these spirillalike organisms as Selenomonas species, because they were Gram-negative, motile, anaerobic organisms that were saccharolytic. ${ }^{31}$ Several biotypes or species were present, as the isolates were variable in nitrate reduction and in esculin hydrolysis.

The prompt resolution of clinical symptoms following metronidazole treatment is presumptive evidence (given the spectrum of antimicrobial activity of this agent) of the anaerobic members of the plaque flora being responsible for the symptoms. Previous studies have shown, by microscopic means, the diminution of the fusospirochetal organisms in the plaque after metronidazole treatment, ${ }^{11,32}$ In the present investigation the proportions of B. melaninogenicus ssp. intermedius, the Fusobacterium sp. and Treponema sp. were significantly reduced for at least 2 to 3 months after treatment (Table 5). Proportions of the Selenomonas sp., were significantly reduced only immediately after treatment. Thus the same anaerobic species that were numerically associated with the ANUG lesion, were also selectively reduced in the plaque flora after resolution of the infection. This is convincing evidence for their specific involvement in the ulcerative stage of the lesion, but because the proportions of these organisms during the formative stage of the lesion were not known these data do not demonstrate that these specific anaerobes initiated the infection.

A considerable amount of epidemiological data indicates that ANUG occurs primarily in young individuals who have been subjected to physiologic or psychologic stresses. ${ }^{1-3}$ Such stress can cause multiple changes in tissue metabolism, which in turn could compromise the defense mechanisms of the host. For example, elevated levels of corticosteroids could so weaken the gingival inflammatory response to plaque antigens and products that bacterial penetration could not be prevented; or elevated levels of norepinephrine could reduce the blood flow to the interdental papilla to the extent that a relative ischemia would ensue, ${ }^{33}$ thus making the tissue vulnerable to bacterial invasion by motile anaerobes such as the spirochetes. ${ }^{34}$

If such scenarios are illustrative of the pathogenesis of ANUG, then many members of the plaque flora should be able to exploit this opportunity to invade the host. 
Yet all the bacteriological studies indicate that only a finite number of species, namely the fusospirochetal organisms and $B$. melaninogenicus ssp. intermedius seem to overgrow. How does such bacterial specificity evolve from host-mediated events? Some understanding in this regard comes from the nutritional requirements of the prominent ANUG organisms such as the Treponema sp. and $B$. melaninogenicus ssp. intermedius.

The few small Treponema sp. that have been cultivated have growth factors, such as long chain fatty acids ${ }^{35}$ and $\alpha$-2-globulin in $T$. denticola ${ }^{36}$ and polyamines in $T$. macrodentium, ${ }^{37}$ that can be provided by the host. All the black-pigmented bacteroides species have a requirement for hemin, and $B$. gingivalis and $B$. melaninogenicus ssp. intermedius have a need for a factor that can be fulfilled by vitamin $\mathrm{K}$ or menadione. ${ }^{16}$

Recently it has been found that steroid hormones such as progesterone and estradiol can substitute for the vitamin $\mathrm{K}$ requirement in certain strains of $B$. melaninogenicus ssp. intermedius. ${ }^{38}$ Thus this species, like the various Treponema sp., is dependent upon host-derived products for specific growth factors. If the levels of these host products were to become increased in the gingival crevice area, as a result of a stress-induced tissue alteration, then the proportions of these organisms might increase, as they would have a selective nutrient advantage over the other plaque species. ${ }^{39}$ Their ascendency in the plaque could enhance still more the inflammatory exudate, thereby perpetuating a cycle that would assure their continued access to their nutrient needs. In this manner host changes could lead to the selection of a specific configuration of organisms from the diverse microbial populations that exist in the plaque. In fact such a host-flora interaction appears to explain the etiology of pregnancy gingivitis. ${ }^{40}$

The increased proportions of $B$. melaninogenicus in ANUG raises the possibility that steroid hormones may be involved as microbial nutrients. In this context, the corticosteroids are being evaluated for their ability to support in vitro the growth of black pigmented bacteroides species.

ANUG, by analogy with the pregnancy gingivitis model, occurs when stress-induced changes in the gingiva make available host products, which can serve as nutrients for certain periodontopathic members of the plaque flora. If a particular constellation of these organisms already exists in the plaque (such as the spirochetes and $B$. melaninogenicus ssp. intermedius), then this nutrient availability assures their ascendency in the plaque at the time that ulceration is present. The cycle is interrupted and health restored when the periodontopathic organisms are removed by either mechanical debridement or antibacterial agents, or the nutrients diminish because of restored host equilibrium. The specificity of the Treponema sp. and B. melaninogenicus ssp. intermedius in ANUG would appear in this context to be host mediated. ANUG could therefore be categorized as an example of the specific plaque hypothesis ${ }^{41}$ as it relates to periodontal disease.

\section{ACKNOWLEDGMENT}

The assistance of Natalie S. Grossman is acknowledged.

\section{REFERENCES}

1. Goldhaber, P., and Giddon, D. B.: Present concepts concerning the etiology and treatment of acute necrotizing ulcerative gingivitis. Int Dent J 14: 468, 1964.

2. Enwonwu, C. O.: Epidemiological and biochemical studies of necrotizing ulcerative gingivitis and noma (cancrum oris) in Nigerian children. Arch Oral Biol 17: 1357, 1972.

3. Wirthlin, M. R., and Devine, L.: Venery and Vincent's. Fifteen case reports and discussion. J Periodontol 49: 449, 1978.

4. Pindborg, J. J.: Influence of service in armed forces on incidence of gingivitis. J Am Dent Assoc 42: 517,1951.

5. Smitt, P. A.: Some clinical and epidemiological aspects of Vincent's gingivitis. Dent Pract (Bristol) 15: 281, 1965.

6. Smith, D. T.: Oral spirochetes and related organisms in fusospirochetal disease. Williams and Wilkins Co. Baltimore, 1932.

7. Rosebury, T., MacDonald, J. B., and Clark, A. R.: A bacteriologic survey of gingival scrapings from periodontal infections by direct examination, guinea pig inoculation, and anaerobic cultivation. $J$ Dent Res 29: 718, 1950.

8. Listgarten, M. A.: Electron microscopic observations on the bacterial flora of acute necrotizing ulcerative gingivitis. $J$ Periodontol 36: 328,1965

9. Shinn, D. L.: Vincent's disease and its treatment. Metronidazole. S. M. Finegold. (ed), pp. 334, Excerpta Medica, 1977.

10. Emslie, R. D.: Treatment of acute necrotizing ulcerative gingivitis. A clinical trial using chewing gums containing metronidazole or penicillin. Br Dent $J$ 122: 307, 1967.

11. Duckworth, R., Waterhouse, J. P., Britton, D. E. R., Nuki, K., Sheiham, A., Winter, R., and Blake, G. C.: Acute ulcerative gingivitis: A double blind controlled clinical trial of metronidazole. $\mathrm{Br}$ Dent $J$ 120: 599,1966

12. Rosebury, T., and Sonnerwirth, A. C.: Bacterial indigenous to man. Ch. in Bacterial and Mycotic Infection of Man. R. J. Dubos (ed), J. B. Lippincott Co., Philadelphia, 1958.

13. King, J. D.: Nutritional and other factors in "Trench Mouth" with special reference to the nicotinic acid component of the Vitamin $\mathrm{B}_{2}$ complex. Br Dent J 74: 113, 1943.

14. Rosebury, T., Clark, P. R., Macdonald, J. B., and O'Connell, D. C.: Studies of fusospirochetal infection. III. Further studies of a guinea pig passage strain of fusospirochetal infection, including the infectivity of sterile exudate filtrates of mixed cultures through ten transfers and of recombined pure cultures. J Infect Dis 87: 234, 1950.

15. Macdonald, J. B., Sutton, P. M., Knoll, M. L., Madlener, E. M., and Grainger, R. M.: The pathogenic components of an experimental fusospirochetal infection. $J$ Infect Dis 98: 15, 1956.

16. Macdonald, J. B., Gibbons, R. J., and Socransky, S. S.: Bacterial mechanisms in periodontal disease. Ann NY Acad Sci 85: 467, 1960.

17. Loesche, W. J.: Oxygen sensitivity of various anaerobic bacteria. Appl Microbiol 18: 723, 1969.

18. Loesche, W. J.: Periodontal disease and the Treponemes. Ch. in the Biology of the Parasitic Spirochetes. R. C. Johnson (ed), Academic Press, New York, pp. 261, '1976.

19. Syed, S. A., and Loesche, W. J.: Survival of human dental plaque flora in various transport media. Appl Microbiol 24: 638, 1972.

20. Aranki, A., Syed, S. A., Kenney, E. B., and Freter, R.: Isolation of anaerobic bacteria from human gingiva and mouse cecum by means of a simplified glove box procedure. Appl Microbiol 17: 568, 1969.

21. Syed, S. A., Svanberg, M., and Svanberg, G.: Predominant cultivable dental plaque flora of beagle dogs with gingivitis. $J$ Periodont Res 15: 123, 1980.

22. Kornman, K. S., and Loesche, W. J.: New medium for the isolation of Actinomyces viscosus and Actinomyces naeslundii from dental plaque. J Clin Microbiol 7: 514, 1978. 
23. Loesche, W. J., and Syed, S. A.: The predominant cultivable flora of carious plaque and carious dentine. Caries Res 7: 201, 1973.

24. Rogosa, M.: The genus veillonella. J Bacteriol 87: 162, 1964.

25. Listgarten, M. A., and Helldin, L.: Relative distribution of bacteria at clinically healthy and periodontally diseased sites in humans. J Clin Periodontol 5: 115, 1978.

26. Minah, G. E., and Loesche, W. J.: Development of methods to analyze sucrose metabolism by small dental plaque suspensions in microbial aspects of dental caries. Stiles, H. J., Loesche, W. J. and O'Brien, T. C. (eds), Microbiol Abst Spec Suppl 2: 491, 1976.

27. Siegal, S.: Nonparametric Statistics for the Behavior Sciences. McGraw-Hill, New York, 1956.

28. Muller, M., Lindmark, D. G., and McLaughlin, J.: Action mechanism of metronidazole in anaerobic microorganisms. Metronidazole, S. Finegold, (ed), Excerpta Medica 12, 1977.

29. Sutter, V. L., and Finegold, S. M.: In vitro studies with metronidazole against anaerobic bacteria. Metronidazole, S. M. Finegold (ed), Excerpta Medica, 279, 1977.

30. Coykendall, A. L., Kaczmacek, F. S., and Slots, J.: Genetic heterogeneity in Bacteroides asaccharolyticus (Holdeman and Moore, 1970) Finegold and Barnes 1977 (Approved Lists, 1980) and proposal of Bacteroides gingivalis sp. nov. and Bacteroides macacae (Slots and Genco) comb. nov. Int J Syst Bacteriol 30: 559, 1980.

31. Loesche, W. J., and Gibbons, R. J.: A practical scheme for the taxonomy of oral gram-negative anaerobic rods. Arch Oral Biol 10: $723,1965$.

32. Blake, G. C.: The microbiology of acute ulcerative gingivitis with reference to the culture of oral trichomonads and spirochetes. Proc R Soc Med 61: 131, 1968.
33. Kardachi, B., and Clarke, N.: Aetiology of acute necrotizing ulcerative gingivitis: A hypothetical explanation. J Periodontol 45: 830, 1974.

34. Listgarten, M. A., and Lewis, D. W.: The distribution of spirochetes in the lesion of acute necrotizing ulcerative gingivitis: An electron microscopic and statistical survey. J Periodontol 38: 379, 1967.

35. Livermore, B. P., and Johnson, R. C.: Lipids of the Spirochaetales: Comparison of the lipids of serveral members of the genera Spirochaeta, Treponema, and Leptospira. J Bacteriol 120: 1268, 1974.

36. Socransky, S. S., and Hubersak, C.: Replacement of ascitic fluid or rabbit serum requirement of Treponema dentium by alpha-globulin. J Bacteriol 94: 1795, 1967.

37. Socransky, S. S., Loesche, W. J., Hubersak, C., and Macdonald, J. B.: Dependency of Treponema microdentium on other oral organisms for isobutyrate, polyamines and a controlled oxidation reduction potential. J Bacteriol 88: 200, 1964.

38. Kornman, K. S., and Loesche, W. J.: Effect of estradiol and progesterone on Bacteroides melaninogenicus and Bacteroides gingivalis. In press. Infect Immun 1982.

39. Loesche, W. J.: Importance of nutrition in gingival crevice microbial ecology. Periodontics 6: 245, 1968.

40. Kornman, K. S., and Loesche, W. J.: The subgingival microbial flora during pregnancy. $J$ Periodont Res 15: $111,1980$.

41. Loesche, W. J.: Chemotherapy of dental plaque infections. Oral Sci Rev 9: 63, 1976.

Send reprint requests to: Dr. Walter J. Loesche, University of Michigan School of Dentistry, Ann Arbor, MI 48109.

\section{Announcement}

\section{THE AMERICAN SOCIETY OF MICROBIOLOGY}

The American Society of Microbiology announces a new book: Host-Parasite Interactions in Periodontal Diseases; editors: Robert J. Genco and Stephan Mergenhagen.

This book takes a close look at the unique host-parasite interactions in periodontal diseases. Included is an up-to-date summary of the microbiology and immunology of these diseases. Its intended audiences are scientists and students whose main interests are in infectious diseases or clinical periodontology. Approximately 450 pages. Clothbound $\$ 25.00$.

Order from: American Society for Microbiology

Publication Office

1913 I Street NW

Washington, D.C. 20006

\section{PAPERS INVITED FOR BALINT ORBAN COMPETITION}

The 1982 Balint Orban Memorial Program of the AAP Annual Meeting in Anaheim, California, October 5-9, will provide an oppor- tunity for students or recently trained periodontists to competitively present their own clinical or basic science research. The oral presentation will be 15 minutes with an additional 5 minutes for discussion. The winner of this competition, judged on the basis of oral presentation and submitted abstract, will receive a $\$ 200$ award and have their paper published in the Journal of Periodontology. All other papers will be submitted to the editors for their consideration.

Students currently enrolled in an accredited Graduate or Postgraduate Program in Periodontology and those who have completed their training not more than 18 months before the AAP Annual Meeting are eligible. A curriculum vitae and abstract of not more than two double spaced typewritten pages are due no later than May 1, 1982. Those selected must also submit a manuscript suitable for publication by the time of the meeting.

Please send curriculum vitae and abstracts to: Dr. Roy C. Page, Director Center for Research in Oral Biology University of Washington Seattle, WA 98195 